\title{
Role of green finance in improving energy efficiency and renewable energy development
}

\author{
Ehsan Rasoulinezhad • \\ Farhad Taghizadeh-Hesary
}

Received: 18 July 2021 / Accepted: 29 January 2022 / Published online: 11 February 2022

(C) The Author(s), under exclusive licence to Springer Nature B.V. 2022

\begin{abstract}
Deploying green energy is, directly and indirectly, related to energy- and environment-related sustainable development goals (SDGs). This study uses the stochastic impact by regression on the population, affluence, and technology (STIRPAT) model to examine the relationship between $\mathrm{CO}_{2}$ emissions, energy efficiency, green energy index (GEI), and green finance in the top ten economies that support green finance. The results show that green bonds are a suitable method to promote green energy projects and reduce $\mathrm{CO}_{2}$ emissions significantly. At the same time, there is no causal linkage between these variables in the short term. Therefore, to achieve sustainable economic growth for environmental issues, governments should implement supportive policies with a long-term approach to boost private participation in the investment of green energy projects. This policy may be applicable during and in the post the COVID19 era when green projects have more difficulties accessing finance.
\end{abstract}

This article is part of the Topical Collection on Energy Efficiency Finance and Sustainable Development Goals

\section{E. Rasoulinezhad}

Faculty of World Studies, University of Tehran, Tehran, Iran

e-mail: e.rasoulinezhad@ut.ac.ir

F. Taghizadeh-Hesary $(\bowtie)$

Social Science Research Institute, Tokai University,

Hiratsuka-shi, Kanagawa-ken 2591292, Japan

e-mail: farhad@tsc.u-tokai.ac.jp
Keywords Energy efficiency $\cdot \mathrm{CO}_{2}$ emissions . Green finance · Green energy index · Panel data, STIRPAT

JEL $\quad \mathrm{N} 0 \cdot \mathrm{N} 10 \cdot \mathrm{O} 10 \cdot \mathrm{O} 23$

\section{Introduction}

Green energy, green finance, and energy efficiency interactions can be addressed as crucial debates in achieving the related sustainable development goals (SDGs), such as affordable and clean energy, climate action, and life on land, relating to planet protection by 2030 . Green energy is a critical energy resource underpinning economic flourishing regarding environmental protection and combating carbon emissions. Maji (2015) proved that a $1 \%$ increase in green energy consumption contributes to nearly $1.26 \%$ economic growth, impressive and considerable for countries under the negative economic consequences of the COVID-19 pandemic. Apergis and Payne (2010) found short-term and long-term bidirectional causal relationships between green energy consumption and economic growth in Organization for Economic Co-operation and Development (OECD) countries. Similarly, green finance can be helpful to green energy project developments that suffer from a lack of capital, especially in the COVID era. Amir and Khan (2021) argued that the economic recession and stagnation caused by the pandemic worldwide (with 
a 5.2\% contraction in global GDP in 2020 (Khanna 2020)) had reduced global capital, leading to a lack of investment in green energy projects. Therefore, green finance tools are an essential and valuable solution to attract private partnerships for green projects under capital pressure (Taghizadeh-Hesary \& Yoshino, 2020). Meo and Karim (2021) discussed the significant role of green finance in increasing investment flows to green projects, suggesting a causal link between green energy and green finance.

Another important ongoing issue for countries is the challenge of low energy efficiency. Gielen et al. (2015) stated that energy efficiency is a central issue in combating environmental pollution. Green finance can help enhance energy efficiency by improving green energy projects and absorbing capital to implement knowledge transformation in energy efficiency. Jin et al. (2021) revealed that green finance positively impacts energy efficiency in China.

Assessing the association or causal relationship between green finance, $\mathrm{CO}_{2}$ emissions, green energy consumption, and energy efficiency is essential and could provide valuable insights for countries. According to earlier studies such as Ren et al. (2020) for China, Charfeddine and Kahia (2019) for the Middle East and North Africa (MENA) regions, and Maji (2015) for Nigeria in the short term, under the circumstances such as unfavorable policy implications, exogenous shocks, and economic structures, there would not be any linkage between green finance, green energy consumption, and energy efficiency. Thus, the study of causal links is informative and valuable for policymakers. However, some countries strongly support the development of the green finance market. Following Meo and Karim (2021), the top ten economies that support green finance are Canada, Denmark, Hong Kong, Japan, New Zealand, Norway, Sweden, Switzerland, the UK, and the USA. The ten economies that may be called "Green Leaders" display rapid economic growth, urbanization growth, lowering $\mathrm{CO}_{2}$ emissions, and increasing contribution of renewable energy consumption to their total energy baskets. According to the data obtained from the World Bank database and the British Petroleum Statistical Review of World Energy 2020, Green Leaders experienced an average economic growth of 2.12\% during 2000-2019. Over the past two decades, the urbanization growth rate averaged nearly $0.98 \%$ in these ten economies. Their overall renewable energy consumption in the total energy basket contributed approximately $22 \%$ over 2000-2019. Meanwhile, the level of $\mathrm{CO}_{2}$ emissions in these countries was approximately 824,200 kt and 729,467 kt in 2000 and 2019, respectively. The trends of these four variables for the Green Leaders are shown in Fig. 1 as follows:

Thus, based on the above explanations, we address two critical issues: first, the linkage between green finance, $\mathrm{CO}_{2}$ emissions, green energy, and energy efficiency is not similar among countries. The strength of the link in the short and long terms may provide valuable insights for policymakers. Second, Green Leaders consist of nations that differ in scale and energy consumption patterns. The existence of linkages among green energy, $\mathrm{CO}_{2}$ emissions, green finance, and energy efficiency in these countries would be interesting, especially the direction of a causal link between these variables is still questionable for experts. Analyzing the linkage between variables can help deploy green energy consumption and enhance energy efficiency by promoting green finance. Overall, these steps will help reduce $\mathrm{CO}_{2}$ emissions in Green Leaders, guiding further policy planning and implementation.

Therefore, this paper seeks to expand the extant literature by these contributions:

i. First, this study is the first of its kind to examine the dynamic linkage among $\mathrm{CO}_{2}$ emissions, green energy, green finance, and energy efficiency among the Green Leaders.

ii. The empirical analysis is based on the stochastic impacts by regression on the population, affluence, and technology (STIRPAT) model (as an appropriate theoretical pattern for analyzing environmental pollution and explanatory variables; Ji and Chen 2017; Debone et al. 2021) addressed in this study for the first time.

iii. Moreover, a green energy index (GEI) is constructed based on the principal component analysis (PCA) technique that was employed in the empirical model.

The paper comprises six sections. The "Literature review" section discusses the literature gap. The data and model specifications are presented in the "Data and model specification" section. The empirical findings are discussed in the "Empirical results" section. Some robustness checks are employed to validate the 

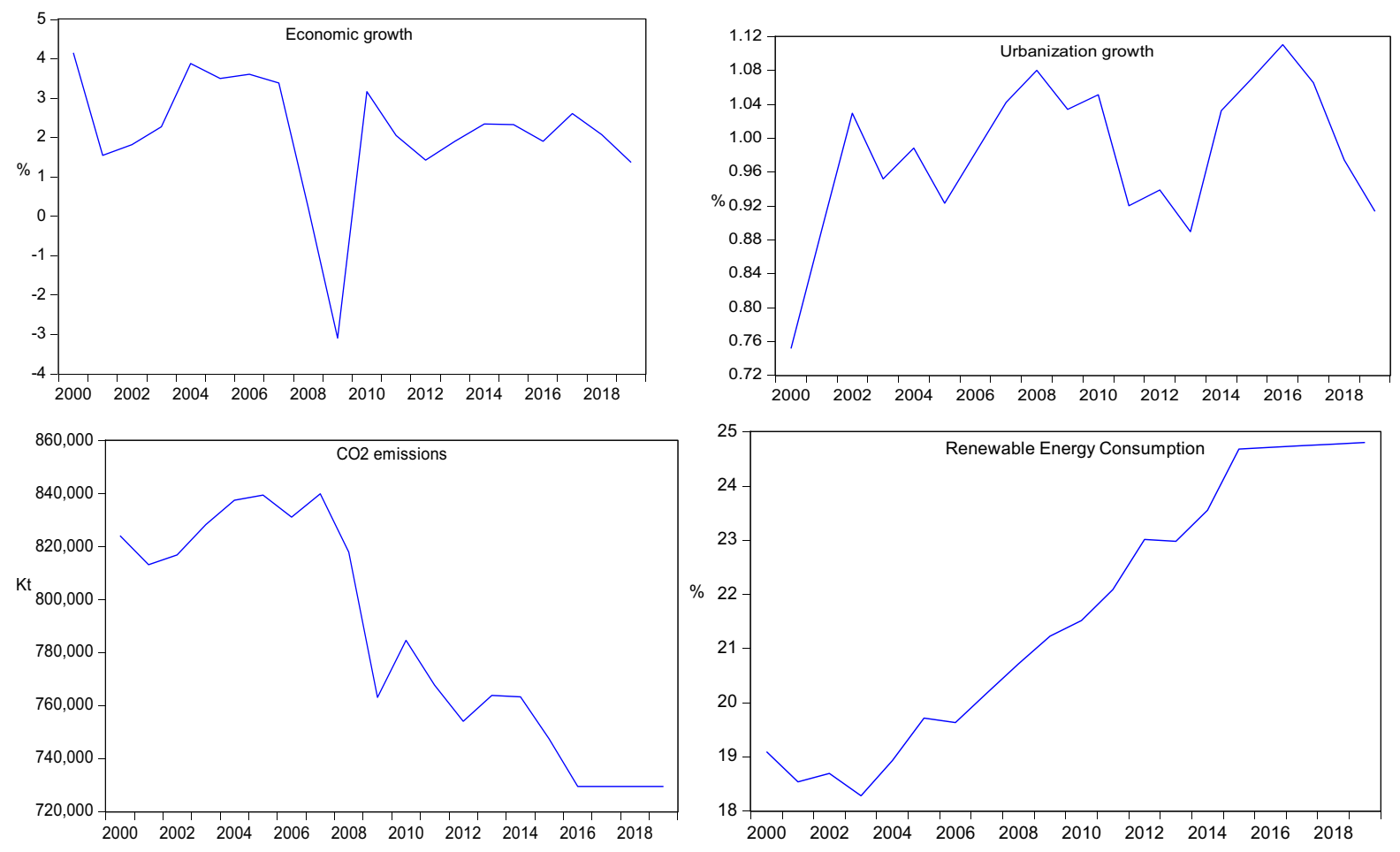

Fig. 1 Green Leaders' economic situation. Source: Compiled by the authors based on the data from the World Bank and British Petroleum Statistical Review of World Energy 2020

empirical findings in the "Robustness check" section, and a summary of the results and practical policy implications are presented in the "Conclusions and policy implications" section.

\section{Literature review}

The issues of green finance and energy efficiency have drawn the attention of a few scholars. A group of scholars showed that green finance is not an efficient tool in many countries because of various core problems. For instance, Fu and $\mathrm{Ng}$ (2021) and Hafner et al. (2020) showed that green finance tools such as green bonds are inefficient in developing or lessdeveloped economies because of the weak private sector and inappropriate financial infrastructure. Consistent with these studies, Hammoudeh et al. (2020) attempted to find a link between green bonds and different economic and environmental indicators and concluded no causal link between green bonds and other variables. Prakash and Mahdvi (2020) found no link between green bonds and SDGs in India due to a financing gap in the private sector and the lack of guidelines with India's climate action plan. Finally, Gibon et al. (2020) analyzed the green bonds issued by the European Investment Banks for green power plants during 2015-2018. The results showed inefficient fund allocation, which neutralized the green financing effect in green projects.

Contrary to the studies that have found neutral or negative impacts of green finance, a group of studies has depicted the beneficial role of green financing on different macroeconomic variables. For example, Naeem et al. (2021) found green bonds to be more effective than conventional bonds during the COVID19 era due to their higher transparency in interest rates and investment return. Similarly, Nguyen et al. (2021) studied how green bonds and other variables such as clean energy were related between 2008 and 2019. They revealed strong evidence of the impact of green bonds on clean energy development. Taghizadeh-Hesary et al. (2021) analyzed the green bond market in different regions, focusing on Asia and 
the Pacific. Their findings proved that green bonds in Asia tend to show higher returns but with higher risks and higher heterogeneity. Generally, the banking sector dominates the Asian green bond market, representing $60 \%$ of all issuances. They concluded that in the post-COVID-19 era, issuers' diversification, with higher participation from the public sector and de-risking policies, could also be considered. Wan (2020) investigated the linkage between green finance and SDGs for climate change and environmental threats. The significant findings showed that state support from the banking and financial sectors in developing green financing could attract private investors to this market.

Consequently, green financing development may positively expand green energy projects. TaghizadehHesary and Yoshino (2019) found that green finance plays a significant role in long-term green investments. However, they stated the role of public financial institutions in making these financing tools more efficient. Tolliver et al. (2020) discussed that using green bonds as an appropriate tool for green financing can lower investment risk, increase return on investment, and attract global investors to green energy projects. Liu et al. (2021) studied the role of green bonds' risk on investors' trust and found that risk management in the green bond market can make this financing tool efficient and effective for green energy project development. Meo and Karim (2021) believed that market conditions and the green finance market mechanism are two significant factors in creating a positive relationship between green finance and green energy projects. A positive impact of green finance on boosting green energy projects, mainly small-scale energy investments, was found by Sachs et al. (2019). Zhang and Wang (2019) and Polzin and Sanders (2020) stated that green finance could help countries reach sustainable renewable energy development by attracting private investors and creating synergy among state and private sectors. Sarangi (2018) studied different aspects of green energy finance in India and found that the growth of the green energy financing market improves green projects, leading to a more significant contribution of green energy to India's total energy basket. Wang and Zhi (2016) argued that the direct and positive impact of green finance on renewable energy development depends on financial market mechanisms and state policies related to green finance. Goldstein (2001) argued that green economic reforms are vital for all countries to boost investment in green energy production, lowering the environmental pollution.

Thus, it can be highlighted that the consequences of using green finance are not similar among countries and depend on different factors. Therefore, the study of green finance in a group of top countries that support this new financing would be practical and bring new insights for these economies and for all other countries wanting to develop green finance markets. Furthermore, exploring how this variable relates to energy efficiency and green energy consumption in these economies is crucial because of their role in realizing SDGs defined by the United Nations in 2015.

This study differs from earlier studies in several aspects. First, the causal linkages between green finance, green energy, and energy efficiency were estimated simultaneously. Second, the causality link among the variables is checked for top green finance supporters globally. The results are essential and bring significant insights. Third, the empirical model consists of the GEI, which includes various green energy resources constructed using the PCA technique. Fourth, the estimation progress is under the STIRPAT approach, confirmed as a reliable analysis framework in energy economics.

\section{Data and model specification}

Theoretically, using an appropriate framework to determine the environmental impacts of different variables has been widely discussed by scholars. As the first advanced theory, Holdren and Ehrlich (1974) proposed a framework called IPAT (environmental impact generated by population, affluence, and technology). In 2002, Waggoner and Ausubel modified the IPAT approach to ImPACT, including consumption per unit of gross domestic product (GDP). However, these approaches suffer from limitations, such as a lack of dynamic analyses and inconsistencies in the impacts of influential factors (York et al., 2003). To solve these issues, a more advanced approach called STIRPAT, considering different variables in a regression form, was proposed by Dietz and Rosa (1994, 1997). Bargaoui et al. (2014) and Gani (2021) expressed STIRPAT as the best theoretical approach to clarify the relationship between environmental 
pollution and explanatory variables. The theoretical equation for STIRPAT can be defined as Eq. 1:

$I_{i}=\alpha \cdot P_{i}^{b} \cdot A_{i}^{c} \cdot T_{i}^{d} \cdot e_{i}$

where $I$ denotes the environmental impact in country $i$ and $P$ and $A$ represent population and affluence. Furthermore, $T$ is technology, and $e$ is the error term. $\alpha$ scales the model, and $b, c$, and $d$ show the estimated exponents of each factor (population, affluence, and technology).

Following Wang et al. (2020), the STIRPAT model in Eq. 1 can be rewritten in its logarithmic form as Eq. 2:

$\ln I_{i t}=\ln \alpha+b\left(\ln P_{i t}\right)+c\left(\ln A_{i t}\right)+d\left(\ln T_{i t}\right)+\ln e_{i t}$

where $\alpha$ indicates a constant and $b, c$, and $d$ represent the exponents of population, affluence, and technology, respectively. $e$ is the error term, and $t$ represents the time. Regarding the dependent variable $(I)$, we follow Zheng et al. (2016) and Wang et al. (2020). They consider $\mathrm{CO}_{2}$ emissions per capita to represent $I$. Moreover, the population is considered for $P$; $A$ means GDP per capita and energy intensity. Finally, issued green bonds and GEI are entered into our empirical model for $T$. Table 1 presents the variables used in our model:

The GEI, based on green energy consumption, is generated using the PCA technique, considering nuclear, hydro, solar, wind, and biofuel consumptions. Before conducting the PCA analysis, the Kaiser-Meyer-Olkin (KMO) test and Bartlett test were performed to determine the suitability of the data for factor analysis. As the KMO and Bartlett values are calculated as 0.83 and 0.001 , respectively, the PCA technique can be employed for these variables. The PCA results are reported in Table 2.

It can be concluded that $\mathrm{A} 1$ has an eigenvalue $>1$ and explains $67.4 \%$ of the total variance of green energy consumption among the ten Green Leaders. Therefore, A1 was added to our model as GEI.

Additionally, to understand the contributions of each variable in component $\mathrm{A} 1$, the factor loadings are presented in Table 3.

The results in Table 3 prove that hydro and wind consumption is higher than other green energy consumption methods in the selected component of A1.

The generalized method of moments (GMM) estimation approach is selected to explore the Granger causal linkages between the variables through Eq. 3 for the annual data covering 2002-2018.

Table 2 Principal component analysis results

\begin{tabular}{llll}
\hline Component & Eigenvalue & \% of variance & $\begin{array}{l}\text { Cumulative } \\
\text { variance }(\%)\end{array}$ \\
\hline A1 & 3.54 & 78.04 & 78.04 \\
A2 & 0.82 & 7.19 & 85.23 \\
A3 & 0.76 & 5.87 & 91.1 \\
A4 & 0.61 & 4.95 & 96.05 \\
A5 & 0.39 & 3.95 & 100 \\
\hline
\end{tabular}

Source: Author's calculation

Table 1 Variables of model

\begin{tabular}{llll}
\hline Variable (symbol) & & Unit & Source \\
\hline Carbon emission per capita (COPC) & & Metric tons per capita & World Bank, Knoema \\
Population (POP) & & Number & World Bank \\
GDP per capita (GDPPC) & & Current US\$ $\$$ World Bank \\
Energy intensity (EI) & & MJ $\$$ 2011 PPP GDP & IEA, World Bank \\
Green bonds (GB) & US\$ & Climatebonds.net \\
Green energy index (GEI) & Nuclear consumption & Million tonnes oil equivalent & BP, IEA \\
& Hydro consumption & Million tonnes oil equivalent & BP, IEA \\
& Solar consumption & Million tonnes oil equivalent & BP, IEA \\
& Wind consumption & Million tonnes oil equivalent & BP, IEA \\
& Biofuels consumption & Thousand barrels per day & BP, IEA, Knoema \\
\hline
\end{tabular}

Source: Authors' compilation 
Table 3 Factor loadings of green energy consumptions in component A1

\begin{tabular}{ll}
\hline Variable & Component A1 \\
\hline Nuclear consumption & 0.014 \\
Hydro consumption & 0.082 \\
Solar consumption & -0.051 \\
Wind consumption & 0.749 \\
Biofuels consumption & 0.009 \\
\hline
\end{tabular}

Source: Author's calculation

$$
\begin{aligned}
\Delta l C O P C_{i t}=\gamma_{0} & +\sum_{j=1}^{m} \delta_{1} \Delta l P O P_{i t-j}+\sum_{j=1}^{m} \delta_{2} \Delta l G D P P C_{i t-j}+\sum_{j=1}^{m} \delta_{3} \Delta l E I_{i t-j} \\
& +\sum_{j=1}^{m} \delta_{4} \Delta l G B_{i t-j}+\sum_{j=1}^{m} \delta_{5} \Delta l G E I_{i t-j}+u_{i t}
\end{aligned}
$$

In Eq. 3, $C O P C$ is the $\mathrm{CO}_{2}$ emissions per capita, $P O P$ is the country's population size, GDPPC represents GDP per capita, and $E I$ and $G B$ are energy intensity and issued green bonds and GEI. Additionally, a panel unit root test and co-integration analysis were conducted to ensure the reliability of the empirical estimation. In this study, the augmented Dickey-Fuller test (Dickey and Fuller, 1979), Phillips and Perron (1988), Breitung (2000), and Levin-LinChu (LLC) (Levin et al. 2002) as the first generation of unit root tests were performed. Carrion-i-Silverstre et al. (2005) unit root test with structural breaks was performed to validate the panel unit root results. Next, the panel co-integration test was employed to explore the long-term equilibrium situation among the variables. Accordingly, two tests proposed by
Westerlund (2007) and Maddala and Wu (1999) were carried out for our model. If there existed a long-term relationship among variables, the augmented mean group (AMG) estimation technique was applied to estimate the long-term coefficients of the explanatory variables.

The panel error correction model was used to determine the causal linkages among variables. Finally, as robustness checks, the fully modified ordinary least squares (FM-OLS) estimator and common correlated effect mean group estimator (CCEMG) estimators were carried out to re-estimate the coefficients. The empirical results are presented in the "Empirical results" section. Additionally, the following conceptual framework (Fig. 2) shows the required steps to conduct the paper.

\section{Empirical results}

First, the panel unit root tests were performed, and the results have been reported in Tables 4 and 5 .

The findings of the panel unit root tests, shown in Table 3, conclude that all the variables have unit roots at levels while they become stationary at the first level.

Considering the structural breaks, the panel unit root test results presented in Table 4 prove the rejection of $\mathrm{H} 0$ of the stationary series.

The overall conclusion from the panel unit root tests, presented in the above tables, is that the variables are not stationary at their levels, while all
Fig. 2 Conceptual framework of empirical research progress. Source: Authors' depiction

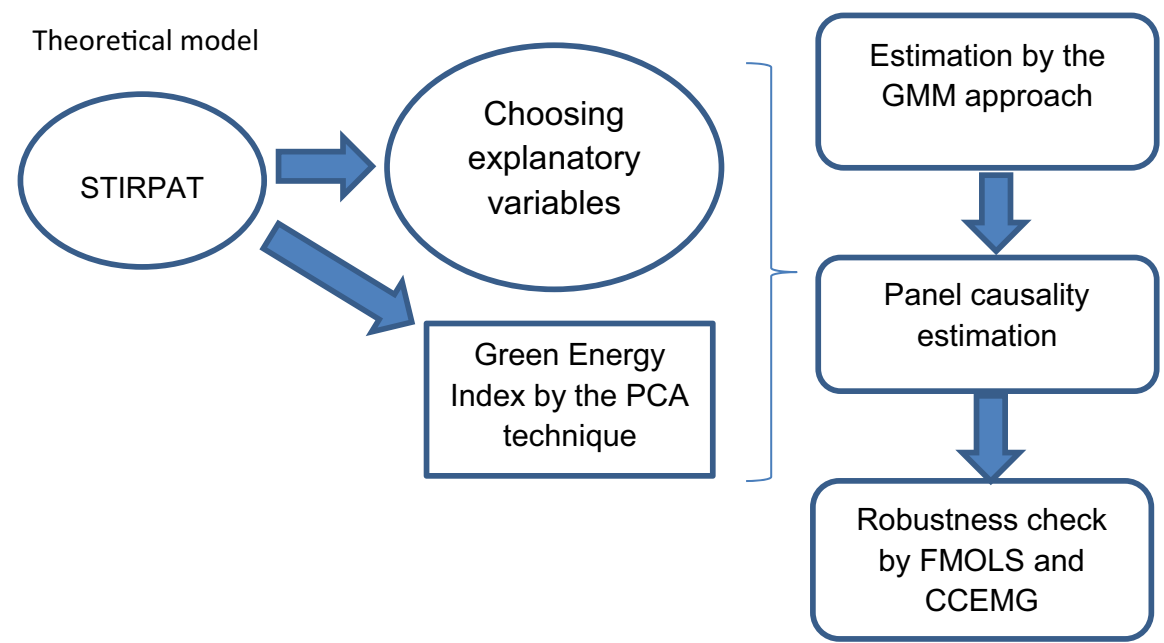


Table 4 The results of ADF, PP, Breitung, and LLC tests

\begin{tabular}{llllllll}
\hline Test & At & Variables & & & & \\
\cline { 3 - 7 } & & COPC & POP & GDPPC & EI & GB & GEI \\
\hline ADF & Level & $61.43(0.243)$ & $56.94(0.419)$ & $60.59(0.349)$ & $70.84(0.116)$ & $45.55(0.866)$ & $44.10(0.940)$ \\
& $\Delta$ & $547.39(0.00)$ & $419.59(0.00)$ & $444.09(0.00)$ & $167.44(0.00)$ & $204.50(0.00)$ & $138.78(0.00)$ \\
PP & Level & $19.59(1.00)$ & $70.44(0.144)$ & $30.59(0.695)$ & $0.317(1.00)$ & $30.59(0.985)$ & $18.86(1.00)$ \\
& $\Delta$ & $933.59(0.00)$ & $500.45(0.00)$ & $359.05(0.00)$ & $96.14(0.001)$ & $80.94(0.133)$ & $975.33(0.00)$ \\
Breitung & Level & $6.076(1.00)$ & $-1.048(0.158)$ & $-0.019(0.455)$ & $-0.993(0.160)$ & $1.654(0.855)$ & $5.068(1.00)$ \\
& $\Delta$ & $-10.39(0.00)$ & $-9.043(0.00)$ & $-18.053(0.00)$ & $-5.694(0.00)$ & $-8.594(0.00)$ & $-16.59(0.00)$ \\
LLC & Level & $2.60(0.990)$ & $-0.960(0.179)$ & $-0.010(0.500)$ & $-0.349(0.351)$ & $3.400(0.995)$ & $-0.618(0.270)$ \\
& $\Delta$ & $-20.58(0.00)$ & $-18.59(0.00)$ & $5.604(0.00)$ & $-16.04(0.00)$ & $-3.594(0.00)$ & $-3.756(0.00)$ \\
\hline
\end{tabular}

Note: COPC, POP, GDPPC, EI, GB, and GEI indicate $\mathrm{CO}_{2}$ emissions per capita, population, GDP per capita, energy intensity, issued green bonds, and green energy index, respectively. $A D F$ augmented Dickey-Fuller, $P P$ Phillips-Perron test, $L L C$ Levin-Lin-Chu test. $\Delta$ is at the first difference; $p$-values are in (). Source: Authors' calculation

Table 5 Panel unit root test with structural breaks

Note: COPC, POP, GDPPC, $\mathrm{EI}, \mathrm{GB}$, and GEI indicate $\mathrm{CO} 2$ emissions per capita, population, GDP per capita, energy intensity, issued green bonds, and green energy index, respectively. Ho and $\mathrm{He}$ stand for homogeneous and heterogeneous, respectively; $*, * *$, and *** denote the significance at $1 \%, 2.5 \%$, and $5 \%$, respectively.

Source: Authors' calculation

\begin{tabular}{lllllll}
\hline Variable & - & Bartlett Kernel & Quadratic Kernel & \multicolumn{3}{l}{ Bootstrap critical values } \\
\cline { 5 - 7 } & & & & 5 percent & 2.5 percent & 1 percent \\
\hline COPC & Ho & $8.758^{* *}$ & $8.761^{* *}$ & 7.713 & 8.100 & 8.853 \\
& He & $5.600^{* * *}$ & $5.673^{* * *}$ & 5.405 & 6.813 & 7.239 \\
POP & Ho & $18.230^{*}$ & $18.607^{*}$ & 17.112 & 17.439 & 18.100 \\
& He & $20.329^{* *}$ & $20.670^{* *}$ & 18.794 & 20.200 & 21.014 \\
GDPPC & Ho & $9.439^{*}$ & $9.501^{*}$ & 7.800 & 8.132 & 8.809 \\
& He & $8.099^{*}$ & $8.165^{*}$ & 5.498 & 6.514 & 7.093 \\
EI & $\mathrm{Ho}$ & $15.655^{* * *}$ & $16.119^{*}$ & 15.400 & 15.684 & 16.019 \\
& $\mathrm{He}$ & $16.301^{* * *}$ & $16.718^{* * *}$ & 16.055 & 16.788 & 17.490 \\
GB & $\mathrm{Ho}$ & $7.301^{* *}$ & $7.419^{* *}$ & 6.817 & 7.001 & 7.519 \\
& $\mathrm{He}$ & $6.839^{*}$ & $6.909^{*}$ & 5.480 & 5.947 & 6.384 \\
GEI & $\mathrm{Ho}$ & $7.918^{*}$ & $7.958^{*}$ & 6.817 & 7.001 & 8.109 \\
& $\mathrm{He}$ & $8.304^{* *}$ & $8.694^{*}$ & 5.483 & 5.911 & 8.897 \\
\hline
\end{tabular}

series are integrated I(1). This conclusion allows us to perform the panel co-integration test to determine whether any long-term equilibrium exists. Two tests, Westerlund and Johansen Fisher, were carried out. The findings of both co-integration tests are reported in Tables 5 and 6 . The evidence from the results, shown in Tables 6 and 7, indicates that a long-term relationship exists between $\mathrm{CO}_{2}$ emissions per capita and the explanatory variables.

Next, regression estimations are carried out using the augmented mean group estimator (AMG). The results are presented in Table 8 .

The estimated coefficients reveal the positive impact of the two variables of population and GDP per capita on $\mathrm{CO}_{2}$ emissions per capita among the
Table 6 Panel co-integration test (Johansen Fisher)

\begin{tabular}{lll}
\hline- & $\begin{array}{l}\text { Stat. from the trace } \\
\text { test }\end{array}$ & $\begin{array}{l}\text { Stat. from the } \\
\text { max eigenvalue } \\
\text { test }\end{array}$ \\
\hline None & $1495.1^{*}$ & $613.2^{*}$ \\
At most 1 & $1230.4^{*}$ & $439.5^{*}$ \\
At most 2 & $938.5^{*}$ & $215.4^{*}$ \\
At most 3 & $411.9^{*}$ & $141.9^{*}$ \\
At most 4 & $287.5^{*}$ & $121.0^{*}$ \\
At most 5 & $179.4^{*}$ & $98.3^{*}$ \\
At most 6 & $104.7^{*}$ & $98.1^{*}$ \\
\hline
\end{tabular}

Note 1: the optimal lag length selection is based on the Schwarz information criterion (SIC); * shows that the statistics are significant at the $5 \%$ level

Source: Authors' calculation 
Table 7 Panel co-integration test (Westerlund test)

\begin{tabular}{lll}
\hline Stat. & Value & Probability \\
\hline Group-t & -3.813 & 0.00 \\
Group-a & -12.055 & 0.766 \\
Panel-t & -15.039 & 0.00 \\
Panel-a & -7.115 & 0.740 \\
\hline
\end{tabular}

Source: Authors' calculation

Table 8 AMG estimation results

\begin{tabular}{lll}
\hline Variable & Coefficient & Statistics \\
\hline POP & 0.04 & $13.49^{*}$ \\
GDPPC & 0.118 & $13.68^{*}$ \\
EI & 0.09 & $4.983^{* *}$ \\
GB & -1.01 & $17.59^{*}$ \\
GEI & -0.92 & $10.29 *$ \\
\hline
\end{tabular}

Note: POP, GDPPC, EI, GB, and GEI indicate population, GDP per capita, energy intensity, issued green bonds, and green energy index, respectively; $*$ and $* *$ show significance at $5 \%$ and $10 \%$, respectively.

Source: Authors' calculation

Green Leaders. This increase in these two explanatory variables leads to higher air pollution due to $\mathrm{CO}_{2}$ emissions. Identifying a positive coefficient of GDP per capita and total population regarding $\mathrm{CO}_{2}$ emissions is consistent with Tucker (1995), Akalpler and Hove (2019), and Aslam et al. (2021) for $\mathrm{CO}_{2}$ emissions-GDP linkage and with Knapp and Mookerjee (1996), Yeh and Liao (2017), and Rehman et al. (2021) for $\mathrm{CO}_{2}$ emissions-population linkage. The main reason for the positive impact of these two variables is the more significant energy consumption, which accelerates $\mathrm{CO}_{2}$ emissions.

The results prove that higher energy intensity, a proxy for energy efficiency, accelerates $\mathrm{CO}_{2}$ emissions, implying that among the Green Leaders, a $1 \%$ increase in energy intensity (contribution of energy to economic size) accelerates pollutant emissions by approximately $0.09 \%$ in the long term. This is consistent with Shahbaz et al. (2015) and Namahoro et al. (2021) for select African countries.

Green bond issuance as a proxy for green finance favors green energy deployment and reduces $\mathrm{CO}_{2}$ emissions per capita. This variable's estimated coefficient suggests that a $1 \%$ increase in the volume of issued green bonds reduces $\mathrm{CO}_{2}$ emissions by approximately $1 \%$ in these countries. Peri (2019), Wang et al. (2021), Loffler et al. (2021), and Meo and Karim (2021) have proved a similar result for different countries, while Mensi et al. (2021) observed the inefficiency of issued green bonds.

The GEI can help these countries to combat $\mathrm{CO}_{2}$ emissions. The estimated coefficient indicates that a $1 \%$ increase in the GEI based on green energy consumption can decrease $\mathrm{CO}_{2}$ emissions by approximately $0.92 \%$ in the long term. Additionally, several earlier studies have shown the positive effect of renewable energy deployment on reducing $\mathrm{CO}_{2}$ (e.g., see Lysen (1989) for solar energy, Hanaki and Portugal-Pereira (2018) for biofuels, Li et al. (2020) for wind energy, and Hassan et al. (2020) for nuclear energy).

Next, the Granger causality test (short-term linkage) based on the panel error correction model (P-ECM) was implemented to determine the direction

Table 9 Results of panel causality test

\begin{tabular}{llllllll}
\hline & \multicolumn{2}{l}{ Short-run } & & & & & \multicolumn{2}{c}{\begin{tabular}{c} 
Long-run \\
\cline { 2 - 7 }
\end{tabular}} & $\Delta \mathrm{lCOPC}$ & $\Delta \mathrm{lPOP}$ & $\Delta \mathrm{lGDPPC}$ & $\Delta \mathrm{lEI}$ & $\Delta \mathrm{lGB}$ & $\Delta \mathrm{lGEI}$ & ECT \\
\hline$\Delta \mathrm{lCOPC}$ & - & $0.14^{*}$ & $0.05^{*}$ & $1.20^{*}$ & -0.05 & -0.14 & $-0.67^{*}$ \\
$\Delta \mathrm{lPOP}$ & -0.08 & - & $0.19^{*}$ & $0.41^{* *}$ & $0.13^{*}$ & $0.03^{* *}$ & $-0.73^{*}$ \\
$\Delta \mathrm{lGDPPC}$ & 0.15 & $0.17^{* *}$ & - & $0.04^{*}$ & $0.36^{* *}$ & $0.12^{*}$ & $-0.66^{* *}$ \\
$\Delta \mathrm{lEI}$ & 0.01 & $0.09^{* *}$ & $0.11^{*}$ & - & $-0.19^{*}$ & $-0.03^{*}$ & $-0.71^{*}$ \\
$\Delta \mathrm{lGB}$ & 0.19 & 0.03 & $0.34^{* *}$ & 0.16 & - & $0.46^{* *}$ & $-0.61^{* *}$ \\
$\Delta \mathrm{lGEI}$ & 0.07 & $0.18^{*}$ & $0.42^{* *}$ & $-0.23^{*}$ & $0.37^{* *}$ & - & $0.70^{*}$ \\
\hline
\end{tabular}

Note: COPC, POP, GDPPC, EI, GB, and GEI indicate CO2 emissions per capita, population, GDP per capita, energy intensity, issued green bonds, and green energy index, respectively; * and ** show the significance at $5 \%$ and $10 \%$, respectively.

Source: Authors' calculation 
Table 10 Robustness check (FMOLS and CCEMG estimators)

\begin{tabular}{lll}
\hline Variable & $\begin{array}{l}\text { FMOLS } \\
\text { Coefficient }\end{array}$ & $\begin{array}{l}\text { CCEMG } \\
\text { Coefficient }\end{array}$ \\
\hline POP & $0.23^{* *}$ & $0.18^{*}$ \\
GDPPC & $0.09^{*}$ & $0.15^{*}$ \\
EI & $0.11^{* *}$ & $0.23^{*}$ \\
GB & $-0.19^{*}$ & $-0.06^{*}$ \\
GEI & $-0.24^{* *}$ & $-0.33^{*}$ \\
\hline
\end{tabular}

Note 1: POP, GDPPC, EI, GB, and GEI indicate population, GDP per capita, energy intensity, issued green bonds, and green energy index, respectively

Note 2: $*$ and $* *$ denote the significance at $5 \%$ and $10 \%$, respectively

Source: Authors' calculation

of the relationship among variables. The findings are presented in Table 9. Based on the coefficients, it can be shown that population, GDP per capita, and energy intensity cause $\mathrm{CO}_{2}$ emissions per capita in these countries. However, there is no causal linkage between issued green bonds and $\mathrm{CO}_{2}$ emissions per capita and GEI and $\mathrm{CO}_{2}$ emissions per capita. Additionally, there is a bidirectional causal relationship between the issued green bonds and the GEI in the short term. Furthermore, a bidirectional relationship between issued green bonds and GDP per capita is found in the short term, which would be interesting for policymakers in these countries. Any support from green finance tools may increase GDP per capita, a significant aspect of social welfare in a country.

Table 11 Robustness check (dependent variable of $\mathrm{CO}_{2}$ emission from fossil fuels)

\begin{tabular}{lll}
\hline Variable & Coefficient & Statistics \\
\hline POP & 0.18 & $16.49^{*}$ \\
GDPPC & 0.09 & $12.17^{* *}$ \\
EI & 0.27 & $14.38^{*}$ \\
GB & -0.67 & $18.03^{*}$ \\
GEI & -0.19 & $17.59^{*}$ \\
\hline
\end{tabular}

Note: POP, GDPPC, EI, GB, and GEI indicate population, GDP per capita, energy intensity, issued green bonds, and green energy index, respectively; $*$ and $* *$ denote the significance at 5\% and 10\%, respectively. Source: Authors' calculation

\section{Robustness check}

Various robustness checks were conducted. First, the empirical model was re-estimated using the other two estimators-FMOLS and CCEMG-to ensure the validity of the empirical estimations. As shown in Table 10, the estimated coefficients of the explanatory variables have the same direction. However, the magnitude of the impacts was different compared to the AMG estimation results.

The second robustness check is based on variable substitution. We replace the dependent variable of $\mathrm{CO}_{2}$ emissions per capita with $\mathrm{CO}_{2}$ emissions from fossil fuels and re-estimate the model using the AMG estimator to check the validity of the estimated coefficients of issued green bonds (a proxy for green finance), GEI, and energy intensity (a proxy for energy efficiency). The estimation results, reported in Table 11, reveal the efficiency of issued green bonds and the increase in the GEI to reduce $\mathrm{CO}_{2}$ emissions from fossil fuels. Furthermore, the positive impact of energy intensity on $\mathrm{CO}_{2}$ emissions from fossil fuels has been confirmed.

\section{Conclusions and policy implications}

Scholars debate the relationship between green finance, green energy consumption, and energy efficiency. This study investigates this relationship by modeling the STIRPAT theoretical approach for the Green Leaders. The annual data for 2002-2018 were gathered, and econometric estimations were conducted based on the panel data framework.

The significant empirical findings reveal that:

In the long term:

i. An increase in the total population of these countries and a higher GDP per capita without energy transition and switching to clean energy may increase $\mathrm{CO}_{2}$ emissions.

ii. The issuance of green bonds makes access to financial resources easier, favoring green energy deployment and reducing $\mathrm{CO}_{2}$ emissions per capita. This variable's estimated coefficient suggests that a $1 \%$ increase in the volume of green bonds reduces $\mathrm{CO}_{2}$ emissions by approximately $1 \%$. 
iii. The GEI shows the status of green energy. The results show that the higher the value of GEI, the lower the $\mathrm{CO}_{2}$ emissions. For example, its estimated coefficient indicates that a $1 \%$ increase in the GEI can decrease $\mathrm{CO}_{2}$ emissions by approximately $0.92 \%$ based on green energy consumption.

Additionally, in the short-term:

i. The Granger causality test shows that increased population, GDP per capita, and energy intensity can lead to higher $\mathrm{CO} 2$ emissions per capita.

ii. There is no causal linkage between issued green bonds and $\mathrm{CO}_{2}$ emissions per capita and between GEI and $\mathrm{CO}_{2}$ emissions per capita.

iii. There is a bidirectional causal relationship between the issued green bonds and the GEI in the short term.

iv. A bidirectional relationship between issued green bonds and GDP per capita was found.

The empirical evidence shows that green finance and green energy deployment can only help countries reduce $\mathrm{CO}_{2}$ emissions in the long term. However, they play an essential role in accelerating GDP per capita in the short and long terms. Thus, to achieve sustainable economic growth concerning environmental issues, governments should implement support policies with a long-term approach to boost private participation in the investment of green energy projects. Thus, providing remittance of earnings and return on investment would be two major ways of encouraging the private sector to invest in green projects. Additionally, increasing the volume of issued green bonds as suitable green finance seems to be another key element in restoring economic growth in the short and long terms. This financial tool may ensure appropriate investment returns for private investors. This policy may be more applicable during and the post-COVID-19 era. Due to the consequences of the pandemic, the lack of capital in green projects and economic recession has become a global debate. Additionally, policymakers should pay attention to energy efficiency to reduce energy intensity and environmental pollution. Accordingly, using international best practices is recommended, such as the EU energy efficiency plan, National Energy
Efficiency Action Plan (NEEAP), Thailand 20-Year Energy Efficiency Development Plan, Energy Saving Improvement Program (ESIP), and Turkey's Strategic Energy Efficiency Plan (SEEP). Regarding the shortterm inefficiency of green finance and green energy consumption in reducing $\mathrm{CO}_{2}$ emissions among the Green Leaders, policymakers should increase green energy use in electricity generation and industrial sectors, which are the two major $\mathrm{CO}_{2}$ emitting sectors. Moreover, prioritizing green energy projects based on financial indicators and $\mathrm{CO}_{2}$ emissions would be a fruitful policy in these countries.

Despite providing fresh and significant conclusions and policy implications, one of the limitations of this study is that econometric analysis is not applied at the country level. Therefore, investigating the relationship between green finance and green energy consumption on $\mathrm{CO}_{2}$ emissions at the country level is recommended for further studies.

Acknowledgements Farhad Taghizadeh-Hesary acknowledges the financial support of the Grant-in-Aid for Excellent Young Researcher of the Ministry of Education, Culture, Sports, Science and Technology of Japan (MEXT).

Author contribution Conceptualization, Ehsan Rasoulinezhad and Farhad Taghizadeh-Hesary; formal analysis, Ehsan Rasoulinezhad and Farhad Taghizadeh-Hesary; methodology, Ehsan Rasoulinezhad; supervision, Farhad Taghizadeh-Hesary; writing - original draft, Ehsan Rasoulinezhad; and writingreview and editing, Farhad Taghizadeh-Hesary.

\section{Declarations}

Conflict of interest The authors declare no competing interests.

\section{References}

Akalpler, E., \& Hove, S. (2019). Carbon emissions, energy use, real GDP per capita and trade matrix in the Indian economy-an ARDL approach. Energy., 168, 1081-1093.

Amir, M., \& Khan, S. (2021). Assessment of renewable energy: Status, challenges, COVID-19 impacts, opportunities, and sustainable energy solutions in Africa. Energy and Build Environment. In Press. https://doi.org/10.1016/j.enbenv. 2021.03.002.

Apergis, N., \& Payne, J. (2010). Renewable energy consumption and economic growth: Evidence from a panel of OECD countries. Energy Policy, 38(1), 656-660.

Aslam, B., Hu, J., Shahab, S., Ahmad, A., Saleem, M., Shah, S., Javad, M., Aslam, M., Hussain, S., \& Hassan, M. 
(2021). The nexus of industrialization, GDP per capita and $\mathrm{CO} 2$ emission in China. Environmental Technology and Innovation, 23, 101674. https://doi.org/10.1016/j.eti. 2021.101674.

Bargaoui, S., Liouane, N., \& Nouri, F. (2014). Environmental impact determinants: An empirical analysis based on the STIRPAT model. Procedia - Social and Behavioral Sciences, 109, 449-458.

Breitung, J. (2000). The local power of some unit root tests for panel data. Adv. Econom., 15, 161-178.

Carrion-i-Silverstre, J. I., Del Barrio, T., \& Lopez-Bazo, E. (2005). Breaking the panels: An application to the GDP per capita. The Econometrics Journal, 8, 159-175.

Charfeddine, L., \& Kahia, M. (2019). Impact of renewable energy consumption and financial development on $\mathrm{CO} 2$ emissions and economic growth in the MENA region: A panel vector autoregressive (PVAR) analysis. Renewable Energy, 139, 198-213.

Debone, D., Leite, V., \& Miraglia, S. (2021). Modelling approach for carbon emissions, energy consumption and economic growth: A systematic review. Urban Climate, 37, 100849. https://doi.org/10.1016/j.uclim.2021.100849.

Dickey, D. A., \& Fuller, W. A. (1979). Distribution of the estimators for autoregressive time series with a unit root. Journal of the American Statistical Association, 74, 427-431.

Dietz, T., \& Rosa, E. A. (1994). Rethinking the environmental impacts of population, affluence and technology. Human Ecology Review, 42, 3-6.

Dietz, T., \& Rosa, E. A. (1997). Effects of population and affluence on $\mathrm{CO} 2$ emissions. Proceedings of the National Academy of Sciences of the United States of America, 94, 175-179.

Fu, J., \& Ng, A. (2021). Scaling up renewable energy assets: Issuing green bond via structured public-private collaboration for managing risk in an emerging market. Energies., 14, 3076. https://doi.org/10.3390/en14113076.

Gani, A. (2021). Fossil fuel energy and environmental performance in an extended STIRPAT model. Journal of Clear Production., 297, 126526. https://doi.org/10.1016/j.jclep ro.2021.126526.

Gibon, T., Popescu, L., Hitaj, C., Petucco, C., \& Benetto, E. (2020). Shades of green: Life cycle assessment of renewable energy projects financed through green bonds. Environmental Research Letters, 15, 104045. https://doi.org/ 10.1088/1748-9326/abaa0c.

Gielen, D., Saygin, D., Wagner, N., Petrichenko, K., \& Tsakiris, A. (2015). Synergies between renewable energy and energy efficiency. IRENA Working Paper.

Goldstein, D. (2001). Financial sector reform and sustainable development: The case of Costa Rica. Ecological Economics, 37(2), 199-215.

Hafner, S., Jones, A., Anger- Kraavi, A., \& Pohl, J. (2020). Closing the green finance gap - A systems perspective. Environmental Innovation and Societal Transitions, 34, 26-60.

Hammoudeh, S., Ajmi, A., \& Mokni, K. (2020). Relationship between green bonds and financial and environmental variables: A novel time-varying causality. Energy Economics, 92, 104941. https://doi.org/10.1016/j.eneco.2020.104941.
Hanaki, K., \& Portugal-Pereira, J. (2018). The effect of biofuel production on greenhouse gas emission reductions. In K. Takeuchi, H. Shiroyama, O. Saito, \& M. Matsuura (Eds.), Biofuels and Sustainability. Science for Sustainable Societies. Springer. https://doi.org/10.1007/ 978-4-431-54895-9_6.

Hassan, S., Khan, S., Baloch, M., \& Tarar, Z. (2020). Is nuclear energy a better alternative for mitigating CO2 emissions in BRICS countries? An empirical analysis. Nuclear Engineering and Technology, 52(12), 2969-2974.

Holdren, J. P., \& Ehrlich, P. R. (1974). Human population and the global environment. American Scientist, 62(3), 282-292.

Ji, X., \& Chen, B. (2017). Assessing the energy-saving effect of urbanization in China based on stochastic impacts by regression on population, affluence and technology (STIRPAT) model. Journal of Cleaner Production, 163(1), S306-S314.

Jin, Y., Gao, X., \& Wang, M. (2021). The financing efficiency of listed energy conservation and environmental protection firms: Evidence and implications for green finance in China. Energy Policy, 153, 112254. https://doi.org/10. 1016/j.enpol.2021.112254.

Khanna, M. (2020). COVID-19: A cloud with a silver lining for renewable energy? Applied Economic Perspectives and Policy, 43(1), 73-85.

Knapp, T., \& Mookerjee, R. (1996). Population growth and global CO2 emissions: A secular perspective. Energy Policy, 24(1), 31-37.

Levin, A., Lin, C., \& Chu, C. (2002). Unit root tests in panel data: Asymptotic and finite sample properties. Journal of Econometrics, 108, 1-124.

Li, J., Li, S., \& Wu, F. (2020). Research on carbon emission reduction benefit of wind power project based on life cycle assessment theory. Renewable Energy, 155, 456-468.

Liu, N., Liu, C., Da, B., Zhang, T., \& Guan, F. (2021). Dependence and risk spillovers between green bonds and clean energy markets. Journal of Cleaner Production, 279, 123595. https://doi.org/10.1016/j.jclepro.2020.123595.

Loffler, K., Petreski, A., \& Stephan, A. (2021). Drivers of green bond issuance and new evidence on the greenium. Eurasian Economic Review, 11, 1-24.

Lysen, E. H. (1989). The potential of renewable energy to reduce $\mathrm{CO} 2$ emissions. In P. A. Okken, R. J. Swart, \& S. Zwerver (Eds.), Climate and energy: The feasibility of controlling CO2 emissions. Springer. https://doi.org/10. 1007/978-94-009-0485-9_6.

Maddala, G.S., and Wu, S. 1999. A comparative study of unit root tests with panel data and a new simple test. Oxford Bulletin of Economics and Statistics 61: 631-652.

Maji, I. (2015). Does clean energy contribute to economic growth? Evidence from Nigeria. Energy Reports., 1, $145-150$.

Mensi, W., Vo, X., \& Kang, S. (2021). Upside-downside multifractality and efficiency of green bonds: The roles of global factors and COVID-19. Finance Research Letters. In Press. https://doi.org/10.1016/j.frl.2021.101995.

Meo, M., \& Karim, M. (2021). The role of green finance in reducing CO2 emissions: An empirical analysis. Borsa Istanbul Review. In Press. https://doi.org/10.1016/j.bir. 2021.03.002. 
Naeem, M., Farid, S., Ferrer, R., \& Shahzad, S. J. (2021). Comparative efficiency of green and conventional bonds pre- and during COVID-19: An asymmetric multifractal detrended fluctuation analysis. Energy Policy, 153, 112285. https://doi.org/10.1016/j.enpol.2021.112285.

Namahoro, J. P., Wu, Q., Zhou, N., \& Xue, S. (2021). Impact of energy intensity, renewable energy, and economic growth on $\mathrm{CO} 2$ emissions: Evidence from Africa across regions and income levels. Renewable and Sustainable Energy Reviews, 147, 111233. https://doi.org/10.1016/j.rser.2021. 111233.

Nguyen, T., Naeem, M., Balli, F., Balli, H., \& Vo, X. (2021). Time-frequency comovement among green bonds, stocks, commodities, clean energy, and conventional bonds. Finance Research Letters, 40, 101739. https://doi.org/10. 1016/j.frl.2020.101739.

Phillips, P. C. B., \& Perron, P. (1988). Testing for a unit root in time series regression. Biometrica., 75, 335-346.

Polzin, F., \& Sanders, M. (2020). How to finance the transition to low-carbon energy in Europe? Energy Policy, 147, 111863. https://doi.org/10.1016/j.enpol.2020.111863.

Prakash, N., \& Mahdvi, S. (2020). Green bonds driving sustainable transition in Asian economies: The case of India. The Journal of Asian Finance, Economics and Business., 8(1), 723-732.

Rehman, A., Ma, H., Ahmad, M., Irfan, M., Traore, O., \& Chandio, A. (2021). Towards environmental sustainability: Devolving the influence of carbon dioxide emission to population growth, climate change, forestry, livestock and crops production in Pakistan. Ecological Indicators, 125, 107460. https://doi.org/10.1016/j.ecolind.2021.107460.

Ren, X., Shao, Q., \& Zhong, R. (2020). Nexus between green finance, non-fossil energy use, and carbon intensity: Empirical evidence from China based on a vector error correction model. Journal of Cleaner Production, 277, 122844. https://doi.org/10.1016/j.jclepro.2020.122844.

Sachs, J., Thye, W., Yoshino, N., \& Taghizadeh-Hesary, F. (2019). Why is green finance important? ADBI Working Paper Series, No. 917. Asian Development Bank Institute (ADBI).

Sarangi, G. K. (2018). Green energy finance in India: Challenges and solutions. ADBI Working Paper Series, No. 863, Tokyo, Japan.

Shahbaz, M., Solarin, S., Sbia, R., \& Bibi, S. (2015). Does energy intensity contribute to $\mathrm{CO} 2$ emissions? A trivariate analysis in selected African countries. Ecological Indicators, 50, 215-224.

Taghizadeh-Hesary, F., \& Yoshino, N. (2019). The way to induce private participation in green finance and investment. Finance Research Letters, 31, 98-103. https://doi. org/10.1016/j.frl.2019.04.016.

Taghizadeh-Hesary, F., \& Yoshino, N. (2020). Sustainable solutions for green financing and investments in renewable energy projects. Energies., 13(4), 788. https://doi.org/ 10.3390/en13040788.
Taghizadeh-Hesary, F., Yoshino, N., \& Phoumin, H. (2021). Analyzing the characteristics of green bond markets to facilitate green finance in the post-COVID-19 world. Sustainability, 13(10), 5719. https://doi.org/10.3390/su131 05719.

Tolliver, C., Keeley, A., \& Managi, S. (2020). Policy targets behind green bonds for renewable energy: Do climate commitments matter? Technological Forecasting and Social Change, 157, 120051. https://doi.org/10.1016/j. techfore.2020.120051.

Tucker, M. (1995). Carbon dioxide emissions and global GDP. Ecological Economics, 15(3), 215-223.

Wan, J. (2020). Green finance and sustainable development goals: The case of China. The Journal of Asian Finance, Economics and Business., 7(7), 577-586.

Wang, Y., \& Zhi, Q. (2016). The role of green finance in environmental protection: Two aspects of market mechanism and policies. Energy Procedia, 104, 311-316.

Wang, S., Zhao, T., Zheng, H., \& Hu, J. (2020). The STIRPAT analysis on carbon emission in Chinese cities: An asymmetric laplace distribution mixture model. Sustainability., 9, 2237. https://doi.org/10.3390/su9122237.

Wang, M., Li, X., \& Wang, S. (2021). Discovering research trends and opportunities of green finance and energy policy: A data-driven scientometric analysis. Energy Policy, 154, 112295. https://doi.org/10.1016/j.enpol.2021. 112295.

Westerlund, J. (2007). Testing for error correction in panel data. Oxford Bulletin of Economics and Statistics, 69, 709-748.

Yeh, J., \& Liao, C. (2017). Impact of population and economic growth on carbon emissions in Taiwan using an analytic tool STIRPAT. Sustainable Environment Research., 27(1), 41-48.

York, R., Rosa, E. A., \& Dietz, T. (2003). STIRPAT, IPAT and ImPACT: Analytic tools for unpacking the driving forces of environmental impacts. Ecological Economics, 46, 351-365.

Zhang, B., \& Wang, Y. (2019). The effect of green finance on energy sustainable development: A case study in China. Emerging Markets Finance and Trade. https://doi.org/10. 1080/1540496X.2019.1695595.

Zheng, H., Hu, J., Guan, R., \& Wang, S. (2016). Examining determinants of $\mathrm{CO} 2$ emissions in 73 cities in China. Sustainability., 8, 1296.

Publisher's note Springer Nature remains neutral with regard to jurisdictional claims in published maps and institutional affiliations. 